Revista Iberoamericana, Vol. LXIX, Núm. 204, Julio-Septiembre 2003, 689-699

\title{
LO QUE VA DE AYER A HOY: MEDELLÍN EN AIRE DE TANGO DE MANUEL MEJÍA VALLEJO Y LA VIRGEN DE LOS SICARIOS DE FERNANDO VALLEJO
}

\author{
POR \\ Jorgelina Corbatta \\ Wayne State University
}

I

¿Pero cómo hablar de la ciudad moderna, que a veces está dejando de ser moderna y de ser ciudad? Lo que era un conjunto de barrios se derrama más allá de lo que podemos relacionar, nadie abarca todos los itinerarios, ni todas las ofertas materiales y simbólicas deshilvanadas que se presentan (16).

García Canclini, Néstor. Culturas híbridas. Estrategias para entrar y salir de la modernidad.

En Aire de tango (1973) de Manuel Mejía Vallejo y en La Virgen de los Sicarios (1995) de Fernando Vallejo, la ciudad colombiana de Medellín-ubicada en el departamento de Antioquia- tiene un papel protagónico. Investigar algunos aspectos de la ciudad y de su transformación histórica y socio-cultural, a partir de su representación textual y mediante instrumentos teóricos provenientes del campo de los estudios culturales, es el propósito de este trabajo. En un ensayo titulado "Caminando en la ciudad", Michel de Certeau analiza un aspecto de la vida urbana de todos los días: la capacidad de aprehender la ciudad caminando por ella. Continuando con la idea ya clásica del flaneur de Walter Benjamin, de Certeau lleva a cabo una lectura semiótica de la ciudad en un itinerario peripatético que conjuga razón y placer en el análisis de la vida cotidiana y en cuyo transcurso se despliega la ciudad no sólo en el momento actual sino también en su historia y hasta en su posible transformación futura. De ese modo, el cuerpo que recorre la ciudad se inscribe en el texto urbano al que no solamente descifra sino que también transforma a su paso. Dice de Certeau:

Trataré de localizar las prácticas que son ajenas al espacio -'geométrico’ o ‘geográfico’de las construcciones visuales, panópticas o teoréticas. Estas prácticas del espacio refieren a una forma específica de operaciones, a otra espacialidad (una experiencia antropológica, poética y mítica del espacio), y a una movilidad opaca y ciega característica de la ciudad en ebullición. Una ciudad migracional, o metafórica, se desliza así al interior del claro texto de la ciudad planeada y legible. (traducción mía) 
En las dos narraciones que he elegido para analizar, esas prácticas del espacio se complementan con una dimensión temporal, la de la memoria, que en nostálgico ejercicio lleva a cabo la recuperación del pasado a la vez que lo compara con el presente en el que se inscribe el deambular del protagonista. En tal sentido vemos en Aire de tango una contraposición entre la ciudad y el campo especialmente entre el pueblo natal del narrador -Balandú- y el barrio de Guayaquil. Este último constituye un espacio de transición entre lo rural y lo urbano, zona de aluvión en donde se concentran campesinos recién llegados a la ciudad, prostitutas y malandrines de toda laya y contra el cual se recortan las peripecias del grupo de bohemios al que pertenece el narrador.

En Aire de tango la experiencia que de Certeau llama antropológica, poética y mítica está dada por la intertextualidad espacial entre el barrio de Guayaquil -lugar de la mayor parte de las incidencias del relato- y el arrabal porteño argentino: ambos espacios dominados por la subcultura del tango y por su dios laico, Carlos Gardel. Se dice de Jairo, el protagonista de la novela y émulo de Gardel: "Sueño suyo ir a Buenos Aires, recorrer Caminito de Juan de Dios Filiberto, meterse en las movidas de compadres y milongueros..." (14). Vemos que el subtexto espacial contra el que se recorta Aire de tango -'esa otra espacialidad' de la que habla de Certeau- está dado por un imaginario colectivo nutrido en letras de tango que dibujan un mapa de las orillas y de su gente, y por una biografía con dimensiones míticas, la de Carlos Gardel. Esta transposición de la subcultura del arrabal porteño, con sus guapos regidos por la ley del coraje según la cual el cuchillo se esgrime a la menor provocación y las muertes habidas constituyen un código no escrito del honor, evoca no sólo las letras de tangos, milongas y hasta valses camperos sino también la mitología de un Buenos Aires malevo presente sobre todo en la obra temprana de Jorge Luis Borges y, en especial, en la abigarrada pintura de esos guapos en "Hombre de la esquina rosada”. En la representación textual de Guayaquil ronda también, como en las letras de tango y en los textos de Borges, la nostalgia de un ayer heroico, casi épico, que tiende a desaparecer borrado por el progreso. Leemos: “Aguarden, es historia: aquí funcionaban la runfla de cafés de punta y raya. Fíjesen ahora, talleres, agencias de autos, almacenes de repuestos, ferreterías” (19). Y, más adelante, usando la típica expresión con que se describe el progreso nos dice el narrador: “También allá, onde fuera, pues tumbaron La Plaza y empezaron las reformas, porque nos llevó el ensanche. Así decimos desde que volvieron anchas las calles estrechas, nos llevó el ensanche” (38) para citar, a continuación, unos versos del tango titulado "Puente Alsina” cuya letra da nombre a una realidad urbana que se experimenta homóloga a la de Medellín: “Dónde está mi barrio, mi cuna maleva,/ dónde la guarida, refugio de ayer?/ Borró el asfalto de una manotada/ la vieja barriada que me vio nacer" (38). ${ }^{1}$

Como en el arrabal porteño regido por la presencia áurea del "Morocho del Abasto" (Gardel), en esa zona de transición y constante migración que es Guayaquil se instala la plaza de mercado, homóloga del porteño mercado del Abasto, en la que se exponen los productos campesinos y donde la comida típica calma los estómagos y aclara las mentes tras borracheras y desórdenes nocturnos. La plaza de mercado delimita una especie de

\footnotetext{
${ }^{1}$ Confróntese los estudios en los que me refiero a la presencia del tango en Medellín y en la obra de Manuel Mejía Vallejo.
} 
paraíso diurno, recuperación nostálgica de un entorno idílico al interior de un itinerario de alcohol, peleas a cuchillos y violencias de todo tipo. La práctica cotidiana del espacio aúna ahora la nostalgia del pasado rural y su presente urbano. Leemos:

Camiones de escalera que traían tercios de plátano, yuca, arracacha, o los cargadores de pescao y carne, o los que llevaban en sus carretas las legumbres y las frutas del día. Olores de banano y guayaba y chirimoya y yerbas remedieras /.../ Por esos andenes caíamos al amanecer a tomarnos el caldo desenguayabador o a calmar el hambre a punta de sancochos con arepa de chócolo y morcilla calentada en las parrillas de barro y lata. (Mejía Vallejo 51)

Dentro de la productividad espacial intertextual que define los rasgos del barrio, los nombres ejercen una fuerza de evocación casi mágica del texto porteño subyacente: “Luces, borracheras, establecimientos bautizados a lo porteño”, y sigue la enumeración minuciosa: "Melodía de Arrabal, La Gayola, El Patio del tango, Café de los Angelitos, Rodríguez Peña, Cuesta Abajo, Armenonville, Magaldi, Bettinoti, La Cumparsita, El Último Tango, La Última Copa, La Copa del Olvido...” (68). Al interior del barrio -que constituye un micro-texto dentro de la ciudad que crece- se dibuja un micro-espacio que es el de la "esquina” (“esas esquinitas de barrio” 139). Allí se repiten y se tejen historias, se practica el galanteo callejero y el humor, en una recreación de lo cotidiano como ejercicio antropológico básico practicado por el grupo y en el que se explicitan sus propios valores y bromas privadas: "Sabrosas esquinas con avisos pegaos y charla de la barra, recostaos allí pasábamos horas hablando lo del día y metiendo embustes y aparando cañas, el piropo a la muchacha bonita, la risa a la vieja que cayó de resbalada, la burla al titino chocante” (139). Y dictamina: “[e]n la esquina conoce uno todos los desconocidos, las carajadas del vecindario, aventuras escondidas” (139).

El barrio, microcosmos habitado por el grupo bohemio nucleado en torno a Jairo y su amigo Ernesto (el narrador), se inscribe a su vez dentro de una ciudad que crece con el progreso a la vez que coexisten en ella-como en una formación que muestra las diferentes eras geológicas que la componen- lavanderas con sus bultos de ropa, silleteros con sus flores bajando desde Rionegro y Santa Elena, multitudes arracimadas en las paradas de buses, la estación de tren, los tranvías -ambos hechos desaparecer por el 'municipio desgraciao’ (68). En esta última frase, económica y poderosa, se concentra todo el rechazo de la autoridad, su desacato desprejuiciado. Se materializa así, dentro del nuevo mapa dibujado por el deambular bohemio del grupo de 'saraviaos', una actitud de constante desafío a la autoridad tanto cívica como religiosa. En relación con esto, a las numerosas iglesias que pueblan la ciudad sólo se las menciona como lugar de recogimiento y soledad: "Iglesias?, no Jairo no iba a misa pero de golpe lo agarraba el afán de entrar en La Metropolitana y sentarse en una banca y oir el órgano, o veía algunas funciones de semana santa y corpus, nada más que yo sepa”. Y remata: "De rezarle a un santo le rezaría a Gardel...” (94).

Como veremos después en La Virgen de los Sicarios, la subcultura de la droga allí enseñoreada, aparece incipiente en Aire de tango. Subcultura de la droga en la que el revólver reemplaza al cuchillo a la vez que trae consigo una nueva ética, una nueva 
ubicación espacio-temporal y hasta un nuevo lenguaje. En Aire de tango se hace presente en la caracterización de uno de los personajes secundarios, un tal Espinosa de quien el narrador oyera hablar en el pueblo durante la Violencia y quien ha reemplazado ahora el cuchillo por el revólver bajo la protección de la virgen: "Hasta pena llegaron a darle las letras tatuadas en la muñeca derecha: V. del C. F., o sea "Virgen del Carmen, Favorecedme”, al lao la crucecita que servía de contra” (48). Se construye así un nuevo sistema sociocultural y un nuevo lenguaje o, mejor dicho, un argot: "Cuando disparaba a matar, [sigue diciendo el narrador acerca de Espinosa] antesitos se sobaba la cumbanba, fijo que había muñeco en el suelo, como ahora dicen los camajanes de las drogas y el atraco” (48).

II

La representación de la ciudad de Medellín en La Virgen de los Sicarios muestra algunos rasgos en común con Aire de tango y muchos otros, muy diferentes. ${ }^{2}$ Compararlos nos permite ver la distancia que media entre el imaginario colectivo representado en ambos textos. Hay, sin embargo, un elemento en común que es la cualidad de flaneur del narrador quien camina por la ciudad dando movilidad al espacio urbano mediante sus prácticas de todos los dias. Es así que, de nuevo, y a través de la topografía de la ciudad y la forma en que la viven los seres que la habitan (lo que Michel de Certeau llama la vida cotidiana), se muestran las marcas que la historia y los cambios socio-culturales van inscribiendo en el cuerpo urbano.

En La Virgen de los Sicarios, el narrador (alter ego del autor) tiene su mismo nombre, se siente extranjero en su propio país ("Pero por qué me preocupa a mí Colombia si ya no es mía, es ajena?” 9), se muestra sumamente crítico de la ciudad en que naciera (“el país más criminal de la tierra. Y Medellín la capital del odio...” 10-22), y pareciera que lo único que le da placer es la práctica de una homosexualidad sin tapujos. ${ }^{3}$ Es culto, escribe, ha viajado por el mundo y tiene una posición económica holgada pero por sus convicciones así como por su elección sexual (y social) circula en los márgenes de la sociedad, en una actitud constantemente transgresora y duramente crítica de sus contemporáneos, del pasado de Colombia y sobre todo de su situación actual.

Curiosamente su percepción de la ciudad recrea la ambiguedad de la misma, su hibridez -en el sentido que le concede García Canclini- ${ }^{4}$. En ese sentido conviven en la ciudad una cultura de la muerte que descree de todos los valores (las iglesias sólo sirven

\footnotetext{
${ }^{2}$ Para un inserción de la novela en la producción total del autor, confróntese "Fernando Vallejo: desacralización y memoria” de María Mercedes Jaramillo.

${ }^{3}$ En la presentación del libro en Barcelona, Vallejo dice "está consagrado al sexo sin segunda intención, sin reproducción, y a mi señora Muerte...” (9)

${ }^{4}$ En una nota referida al sustantivo hibridación, dice García Canclini: "se encontrarán ocasionales menciones de los términos sincretismo, mestizaje y otros empleados para designar procesos de hibridación. Prefiero este último porque abarca diversas mezclas interculturales -no sólo las raciales a las que suele limitarse "mestizaje"- y porque permite incluir las formas modernas de hibridación mejor que "sincretismo", fórmula referida casi siempre a fusiones religiosas o de movimientos simbólicos tradicionales" (14-15).
} 
para asegurar la perduración de los sicarios y sus actividades, y en cuyas bancas se fuma marihuana: “distinga bien el olor del humo, que no se le confunda con el incienso" 12) y una hipocresía estructural que define a Colombia como el país del Sagrado Corazón. ${ }^{5}$ Otra forma de ambivalencia es la oposición entre la homosexualidad libremente practicada/ proclamada del narrador la que lo lleva a adoptar una actitud desenfadada y blasfema al tiempo que su conciencia política lo opone a Fidel Castro, los Derechos Humanos, los sindicatos y todo tipo de reivindicación social y política que instaure una sociedad más abierta y libre. En cuanto a la hibridez manifiesta en la ciudad propiamente dicha, vemos que su superficie ha cambiado modernizándose con su tren elevado, sus shopping centeres, los SUV y sus habitantes en ropas deportivas y llevando nombres extranjeros (9): todo lo que el capitalismo del primer mundo impone al consumidor y que a la vez coexiste con la pobreza, el crimen, la extrema miseria en todos los órdenes. Caminando por la Avenida La Playa, “para calibrar el desastre”, el narrador va enumerando fragmentos del caos que compone la ciudad: "Las aceras? Invadidas de puestos de baratijas que impedían transitar. Los teléfonos públicos? Destrozados. El centro? Devastado. La Universidad? Arrasada” (75). Para enfocarse luego en la gente: “Ibamos mi niño y yo abriéndonos paso a empellones por entre esa gentuza agresiva, fea, abyecta, esa raza depravada y subhumana, la monstruoteca” (75) y rematar con dos percepciones sensoriales. Una auditiva: “Jirones de frases hablando de robos, de atracos, de muertos, de asaltos /.../ me llegaban a los oídos pautadas por las infaltables delicadezas de 'malparido e 'hijueputa'” (76) y otra olfativa que sintetiza el intenso desagrado físico que experimentan en el contacto con la ciudad y su gente: "Y ese olor a manteca rancia y a fritangas y a gases de cloaca..." (76).

$\mathrm{Al}$ igual que en el texto anterior, en éste la ciudad se contrapone con el campo. En el párrafo con que se abre la narración leemos: "Había en las afueras de Medellín un pueblo silencioso y apacible que se llamaba Sabaneta” (7). Se introducen así dos categorías -el silencio y la paz-, cuya ausencia se deplora en una ciudad en la que el ruido es polución y la violencia rige las vidas de sus habitantes. Sólo en algunos espacios privados, el llamado "cuarto de las mariposas" por ejemplo, en donde el narrador inicia su relación sexual con Alexis, y en ocasiones en su propio departamento, el silencio todavía reina. En el espacio público es la radio atronadora de los taxis con sus anuncios de muertos y sus bambucos; el ruido de los vehículos; los atracos sin cuento y los corrillos que se forman alrededor del muerto; las peleas a tiros de bandas rivales; el rock duro y la música punk que ahora han reemplazado los tangos y milongas anteriores para figurar un imaginario que ya no se nutre del arrabal porteño sino de los íconos de los massmedia provenientes de las grandes capitales del primer mundo.

“Abre las ventanas niño -le pedía- para que entre la brisa”. Y mi niño se levantaba desnudo como un espejismo de las Mil y Una Noches y su imaginación desaforada, con

\footnotetext{
5 "Nosotros teníamos uno [el Corazón de Jesús] en la sala; en la sala de la casa de la calle del Perú de la ciudad de Medellín, capital de Antioquia; en la casa en donde yo nací, en la sala entronizado o sea (porque sé que no van a saber) bendecido un día por el cura. A él está consagrada Colombia, mi patria. Él es Jesús y se está señalando el pecho con el dedo, y en el pecho abierto el corazón sangrando: goticas de sangre rojo vivo, encendido/.../: es la sangre que derramará Colombia, ahora y siempre por los siglos de los siglos amén” (8).
} 
sus tres escapularios, y abría el balcón. Brisa no entraba porque brisa no había, pero sí la música, el estrépito, del hippie de al lado y sus compinches, los mamarrachos. "Ese metalero condenado ya nos dañó la noche”, me quejaba. No es el metalero-me explicó Alexis cuando se lo señalé en la calle al otro día. Es un punkero. (28)

Dentro de los ruidos que el narrador detecta en la ciudad están las palabras de un nuevo lenguaje, el argot que desalojando el español castizo y el latín al que es afecto, invade el habla cotidiana nominando una realidad nueva que es la subcultura del narcotráfico. Esta subcultura tiene su propio espacio, el de las 'comunas' e introduce un nuevo grupo humano, el de 'los sicarios', portadores a su vez de nuevos códigos de conducta y de comunicación. Al sicario se lo define como "un muchachito, a veces un niño, que mata por encargo" (10). Y cuya habla, idiolecto mejor, está formado “de un viejo fondo de idioma local de Antioquia, /.../ más una que otra supervivencia del malevo antiguo del barrio de Guayaquil, ya demolido, que hablaron sus cuchilleros, ya muertos; y en fin, de una serie de vocablos y giros nuevos, feos, para designar ciertos conceptos viejos...” (26). Dentro de esos 'giros nuevos, feos” aparece el ya visto “muñeco” por muerto; “quebrar' por matar; "Entonces qué, parce, viento o maletas” que significa "Hola hijo de puta” (26) o 'gonorreas” ("el insulto máximo en las barriadas de las comunas” 14). En una ocasión, tras presenciar un atraco, Fernando vuelve al departamento y le cuenta a Alexis lo que ha visto. La contraposición de los códigos lingüísticos que tiene lugar muestran no sólo los cambios socio-culturales en la sociedad de Medellín, sino también la diferencia generacional y de clase social de ambos interlocutores.

“El pelao debió de entregarle las llaves a la pinta esa”, comentó Alexis, mi niño cuando le conté el suceso. O mejor dicho no comentó: diagnosticó, y como un conocedor, al que hay que creerle. Y yo me quedé enredado en su frase soñando, divagando, pensando en don Rufino José Cuervo y lo mucho de agua que desde entonces había arrastrado el río. Con el "pelao" mi niño significaba el muchacho; con "la pinta esa" el atracador; y con “debió de " significaba “debió a secas” tenía que entregarle las llaves. (23)

Este nuevo grupo humano, los sicarios, producto de la subcultura de la droga son de existencia efímera al punto que se los califica de “desechables” en cuanto su valor de uso sirve para definir su identidad de asesinos a sueldo. ${ }^{6}$ Bajan de las comunas a las que se las describe como "Barrios y barrios de casuchas amontonadas unas sobre otras en las laderas de las montañas” y en donde el ruido, el odio y la procreación son omnipresentes: “atronándose con su música, envenenándose de amor al prójimo, compitiendo las ansias de matar con la furia reproductora” (32). A esas comunas el narrador sólo las conoce desde lejos, las mira desde la terraza de su apartamento mientras fabula: "la nororiental y la

\footnotetext{
${ }^{6}$ En el informe de la comisión especial designada por el Ministerio de Gobierno Colombiano en 1987, titulado Colombia: Violencia y democracia se analizan y definen diferentes tipos de violencia. En el apartado referido a los sicarios, se los caracteriza como asesinos a sueldo sin lealtad o adhesión a grupo organizado alguno, indiferente respecto de sus víctimas y cuya actividad se estipula bajo la forma de un contrato para matar a cambio de una remuneración (Bergquist, Ch. Violence in Colombiam 221ss, mi traducción).
} 
noroccidental, las más violentas, las más famosas: enfrentándose en opuestas montañas, viéndose, calculándose, rebotándose sus odios” (35), Y sigue la enumeración cuando le pregunta a Alexis cuál es su barrio: "Es acaso Santo Domingo Savio? O el Popular, o La Salle, o la Villa del Socorro, o La Francia?” (35). Curiosamente (y como parte de la hibridez que señalara antes), los sicarios frecuentan las iglesias, van en peregrinación y se encomiendan a la virgen a la que piden "que nos les vaya a fallar, que les afine la puntería cuando disparen y que les salga bien el negocio" (17). Tres pedidos que refuerzan la función de los tres escapularios que llevan "uno en el cuello, otro en el antebrazo, otro en el tobillo /.../para que les den el negocio, para que no les falle la puntería y para que les paguen” (18). Mezcla de superstición y culto católico, esta subcultura de la droga crea una nueva ética en la que la culpa no es de los sicarios sino de quien los mandó matar. Además, las muertes tienen su origen -y se cobran- cuentas pendientes (“culebras”), propias y ajenas. El narrador le aclara al lector: "Como usted comprenderá, en ausencia de la ley que se pasa todo el tiempo reonovándose, Colombia es un serpentario” (40). En el momento de la narración ha muerto el gran capo de la mafia, Pablo Escobar, y los sicarios ya no tienen trabajo o lo hacen por su cuenta, desvirtuando en empresa privada lo que era una acción comunitaria o como dice, irónicamente Fernando, “[o] tra institución que se nos va” (40).

Con la muerte del presunto narcotraficante que dijo arriba nuestro primer mandatario, aquí practicamente la profesión de sicario se acabó. Muerto el santo se acabó el milagro. Sin trabajo fijo, se dispersaron por la ciudad y se pusieron a secuestrar, a atracar, a robar. $\mathrm{Y}$ sicario que trabaja solo por su cuenta y riesgo ya no es sicario: es libre empresa, la iniciativa privada. Otra institución pues nuestra que se nos va. (40)

Según de Certeau, caminar en la ciudad inscribe al caminante en el texto urbano al que no sólo descifra en su deambular sino al que también transforma. En La Virgen de los Sicarios, la medida de Medellín se despliega en el transitar del narrador y su amante y se escande por las muertes que Alexis (y luego Willmar su reemplazante) va ejecutando -ya sea inspirado por su amigo, por la necesidad de las circunstancias, o por su propio capricho. ${ }^{7}$ El primer muerto es el vecino punkero; le siguen tres soldados en el parque de Bolívar que los detienen para requisarlos; un grosero con el que se tropiezan en la calle Junín y los llama maricas; dos sicarios en moto mandados a matarlos en la plaza de Aranjuez; el 'taxista altanero' que no quiso bajar el volumen de la radio; la empleada de la cafetería que les negó una servilleta de papel entera; los defensores del gamincito que insultó a un policía, y el gamincito incluido en el Centro Comercial de Junín y Bolívar. Enumeración que hace decir a Fernando, en el colmo del éxtasis “Alexis era el Ángel Exterminador que había descendido sobre Medellín a acabar con su raza perversa” (64). Y la cuenta sigue: “un mimo” en las puertas de la catedral y uno que salió en su defensa; otro que se había puesto a bailar con los Hare Crishnas en el parque de Bolívar; seis

${ }^{7}$ Desde una perspectiva distinta a la nuestra, pero complementaria en la caracterización de la ciudad, Héctor D. Fernández L’Hoeste enumera el recorrido del protagonista por las iglesias de Medellín (763). 
borrachos en una cantina; un guardián en el cementerio; dos niños peleando a la puerta de ese mismo cementerio y, de nuevo, otros sicarios en moto que vienen a matarlos. En oposición a esa masacre indiscriminada de seres humanos, eliminados en medio del más absoluto desprecio (“cuando Alexis llegó a los cien definitivamente perdí la cuenta” 89), se erige puro el amor a los animales (los caballos de tiro, un perro ahogándose en una quebrada) de los que dice Fernando: "los animales son el amor de mi vida, son mi prójimo, no tengo otro, y su sufrimiento es mi sufrimiento y no puedo resistir” (88).

Medellín, a la que Vallejo dice conocer mejor que Balzac conocía París, es, según él, dos ciudades: "la de abajo, intemporal, en el valle; y la de arriba en las montañas, rodeándola”, e invadiéndola en un movimiento unidireccional ya que, puntualiza, "[l]a ciudad de abajo nunca va a la ciudad de arriba pero lo contrario sí: los de arriba bajan, a vagar, a robar, a atracar, a matar” (97). Movimiento centrífugo que parte de las comunas y se derrama hacia abajo ya que allá arriba la violencia es la norma: la guerra de barrio con barrio, de cuadra con cuadra, de banda con banda. Resume: "la guerra total, la de todos contra todos” (97). Violencia actual que el narrador remonta y filia en la llegada de los campesinos con machete, reemplazados luego por armas de fuego y más tarde por revólveres vendidos por la policía y el Ejército. Y, yendo más atrás, su origen estaría en la mezcla de español con indio y negro que produce 'simios, monos, micos con cola para que con ella se vuelvan a subir al árbol” (105-106). Coexistiendo con ese pasado híbrido, se erige un sociedad consumista que ha invadido la ciudad tradicional y que se ejemplifica en la lista de deseos que escribe el nuevo amigo de narrador cuando recién se conocen. Allí se concentra un nuevo imaginario colectivo producto del mercado en la era de la globalización: “tenis marca Reebock y unos jeans Paco Ravanne, camisas Ocean Pacific y ropa interior Kelvin Klein. Una moto Honda, un jeep Mazda, un equipo de sonido laser y una nevera para la mamá: uno de esos refrigeradores enormes marca Whirpool que soltaban chorros de cubitos de hielos abriéndoles simplemente una llave” (107). Lista que Fernando, deseoso de complacer a su nuevo amante, materializa no sin hacer un comentario irónico acerca del valor terapeútico de ese "shopping spree" "El Estado debe concientizarse más y comprarles ropa a los muchachos con el fin de que ya no piensen tanto en procrear ni en matar” (115).

En cuanto a la representación del campo que, en Aire de tango aparecía como el lugar idílico y puro, reaparece en La Virgen de los Sicarios como el origen de todos los males que abaten a la ciudad en el presente y a sus habitantes se los describe como seres violentos y reproductores. A lo largo de toda la narración, como un eco de la famosa frase borgiana en donde se afirma que "los espejos y la cópula son abominables, porque multiplican el número de los hombres” (13), Fernando Vallejo no deja de denostar la cópula heterosexual que resulta en el aumento demográfico de la población. Dictamina: “...aquí la vida crapulosa está derrotando a la muerte y surgen niños de todas partes, de cualquier hueco o vagina como las ratas de las alcantarillas...” (84).

En "Walking in the city" de Certeau analiza la ciudad de Nueva York desde dos perspectivas: una es desde el piso ciento diez del World Trade Center; la otra, caminando por la calle en donde se confunde con la gente, rehaciendo y borrando itinerarios y subespacios que tienen que ver con los diferentes subgrupos que los habitan y sus diferentes subculturas, lenguas, hablas, argots e idiolectos. En La virgen de los sicarios encuentro 
que, en oposición a la visión llana o de superficie presente en Aire de tango, conviven las dos perspectivas enunciadas por de Certeau. Desde su apartamento el narrador es sólo ojos, mirada libre, incorpórea e incontaminada que aprehende, desde la altura, las lucecitas de las comunas, los transeúntes allá abajo, el tránsito ensordecedor pero lejano.

Yo hablo de las comunas con la propiedad del que las conoce, pero no, sólo las he visto de lejos, palpitando sus lucecitas en la montaña y en la trémula noche. Las he visto, soñado, meditado desde las terrazas de mi apartamento, dejando que su alma asesina y lujuriosa se apodere de mí. (34)

Como dice de Certeau, el que mira desde lo alto se transforma en un voyeur, una especie de Ícaro que flota en el espacio ignorando los recursos de Dédalo inmerso en móviles laberintos sin fin, allá abajo (152, traducción mía). ${ }^{8}$ Desde los balcones de su apartamento, desde el avión que lo lleva/trae de Suiza, desde el aeropuerto de Medellín, el narrador lee la ciudad desde la altura como si fuera un dios. Cuando desciende a la calle, sin embargo, se mezcla con la multitud y readquiere su cuerpo (lo llaman 'marica', lo aturden los ruidos, lo apuntan desde una moto). En la calle se expone, entra en contacto con los otros, interactúa en una sociedad cuyas reglas antes ignotas empieza a conocer y aprende a practicar. Por ejemplo: al principio de la narración se siente sobrecogido por el volumen de la radio en los taxis para aprender luego a hacer que lo reduzcan o, simplemente, la apaguen.

De este modo vamos viendo que, dentro de la misma ciudad, conviven varias perspectivas: una, desde la altura, omnipotente como el ojo de dios y que concurre con la que se nos brinda en la Edad Media -jerárquica y elevándose hacia el cielo (como el recuerdo nostálgico del globo de Sabaneta en la niñez: “...el globo subió y subió y empujado por el viento dejando atrás y abajo los gallinazos se fue yendo hacia Sabaneta...” 8). La ciudad vista desde arriba es, de acuerdo con de Certeau, un simulacro teórico, una percepción visual que -para existir- se basa en el olvido y la confusión de las prácticas cotidianas. Porque los que de ordinario llevan a cabo esas prácticas viven en la ciudad de abajo. Son los que la recorren, los que caminan la ciudad bajo la forma elemental de experimentar el espacio y en ese sentido más que leer el texto urbano, lo escriben y lo reescriben constantemente sin ser empero capaces de leerlo. No hay la totalización del ojo que ve desde arriba sino la fragmentación de trayectorias parciales que circulan en el espacio y lo alteran. Al respecto hay un episodio curioso en la novela el que, en la primera lectura aparece irónico, casi despiadado pero que ilustra la relación entre ese espacio vivido, caminado, y la instauración de nuevos itinerarios y nuevas costumbres. Me refiero a la ocasión en que Fernando y Alexis se encuentran con tres soldados en el parque de Bolívar quienes, dispuestos a requisarlos, reciben también ellos la bala en la frente.

Era tan asombroso el suceso, tan imprevisto el suceso que no sabía qué hacer. Alexis tampoco. Se quedó viendo los cadáveres como hipnotizado, mirándoles los ojos. 'Se me

\footnotetext{
8 "An Icarus flying above these waters, he can ignore the devices of Daedalus in mobile and endless
} labyrinths far below. His elevation transfigures him into a voyeur” (152). 
hace que lo mejor es que nos vamos yendo, niño, a almorzar.' Aquí el almuerzo era a las doce, pero con este cambio de las costumbres se ha ido pasando para la una y media. (43)

III

Para terminar, una síntesis de lo analizado. En ambos textos el narrador deambula por la ciudad de Medellín a la que fabula en su relato. Aparece así el escritor-flaneur como lo quería Baudelaire, como lo describe Walter Benjamin y como lo teoriza de Certeau en relación con el espacio que transita. En Aire de tango se camina un espacio percibido desde la nostalgia de un ayer campesino y la trama de un imaginario colectivo nutrido en la mitología porteña del arrabal con sus guapos, cuchillos y tangos para ser cantados o contados. La violencia allí presente está anclada en el reciclaje imaginativo de una cultura argentina que se fragmenta en la apropiación y se resemantiza desde una perspectiva colombiana.

En La Virgen de los Sicarios el espacio se multiplica, hay un arriba omnipotente pero también impotente (es el del balcón protegido del narrador pero también el inaccesible de las comunas), y hay un abajo que se camina pero que es también recorrido por taxis, SUV, motos con 'parrileros'. Es un espacio atravesado por la potencia de revólveres y metralletas en donde la lucha cuerpo a cuerpo de las pelas a cuchillo se ve reemplazada por la eficacia ciega de las balas. Es también el espacio híbrido de la gran ciudad con sus viejas iglesias (ahora habitadas por drogadictos y visitadas por sicarios en peregrinación) y sus shopping malls que la igualan en la era de la sociedad consumista de la globalización. La narración constituye un texto desencantado, posmodernista, catastrófico, iconoclasta, apocalíptico, sin redención. Presenta un nueva visión de la historia y del mundo: individual, no colectiva. Las categorías de ajenidad, extranjeridad, consumismo, trivialidad, hibridez tejen su trama. A la ingenuidad de tono romántico y fuertemente nostálgico de un ayer recobrado en la evocación idealizada de Mejía Vallejo sucede ahora una visión nihilista de la ciudad, el país, su gente. Todo ello presente en la ciudad de Medellín escrita como un texto que se lee y se reescribe sin cesar en medio de una violencia que constituye la parte visible, y doliente, del actual devenir histórico colombiano.

Bibliografía

Bergquist, Charles (Ed.). Violence in Colombia. The Contemporary Crisis in Historical Perspective. Wilmington: Scholarly Resources, 1992.

Certeau, Michel de. "Walking in the city". The Practice of Everyday Life. Berkeley: University of California Press, 1984.

Corbatta, Jorgelina. “Tango y literatura en Antioquia: M. Mejía Vallejo, O. Hernánez, M. Rivero, J. J. Hoyos”. Hibridez y alteridades. M. M. Jaramillo, B. Osorio, A. Robledo, comps. Bogotá: Ministerio de Cultura, 2000. 543-83.

"Recordado a Manuel Mejía Vallejo: el hombre y su obra”. Hibridez y alteridades. M. M. Jaramillo, B. Osorio, A. Robledo, comps. Bogotá: Ministerio de Cultura, 2000. 367-87. 
“Evocación de Manuel Mejía Vallejo”. Revista de Estudios Colombianos 20 (1999): 8-13.

“Historia y mito en Aire de tango de Manuel Mejía Vallejo”. INTI. Revista de Literatura Hispánica 24-25 (Otoño 1986-Primavera 1987): 137-43.

“Manuel Mejía Vallejo habla de tango". Revista de Estudios Colombianos 9 (Fall 1990): 65-69.

"El tango y el mito Gardel en Medellín: imaginario colectivo y transposición literaria”. Boletín Cultural y Bibliográfico 35/49 (1998): 158-83.

Fernández L’Hoeste, Héctor D. “La Virgen de los Sicarios o las visiones dantescas de Fernando Vallejo”. Hispania 83 (December 2000): 757-67.

García Canclini, Néstor. Culturas híbridas. Estrategias para entrary salir de la modernidad. México: Grijalbo, 1989.

Jaramillo, María Mercedes. “Fernando Vallejo: desacralización y memoria”. Diseminación, Cambios, Desplazamientos. M. M. Jaramillo, B. Osorio, A. Robledo, comps. Bogotá: Ministerio de Cultura, 2000. 407-39.

Mejía Vallejo, Manuel. Aire de tango. Bogotá: Plaza y Janes, 1979.

Vallejo, Fernando. “El hombre, ese animal alzado”. Quimera. Revista de Literatura 179 (abril 1999): 8-11.

La virgen de los sicarios. Bogotá: Alfaguara, 1995. 